Military Technical College

Kobry El-Kobbah, Cairo, Egypt.

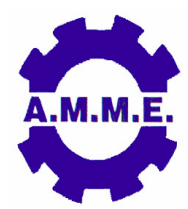

$15^{\text {th }}$ International Conference on Applied Mechanics and Mechanical Engineering.

\title{
DEVELOPMENT OF NEW TECHNIQUE FOR NANO IRRADIATION OF STAINLESS STEELS 304
}

\author{
H. Ahmed ${ }^{*}$
}

\begin{abstract}
In this work, new method for surface treatment of the material by laser irradiation was investigated; the experimental works were conducted to study the effect of laser irradiation on the improvement of the mechanical properties of the alloys. Excimer laser at $193 \mathrm{~nm}$ were used at the same power of $6 \mathrm{~mJ}$ and repetition rate of $200 \mathrm{~Hz}$. Nanoindentation technique was used to determine film hardness, stiffness and elastic modulus using a nano test instrument form with diamond indenter. The peak loads in the range $1-200 \mathrm{mN}$ were used, with variable loading rate in proportion to the peak loads starting at a value of $0.05 \mathrm{mN} / \mathrm{s}$. The hardness and reduced modulus have been determined from these indentation curves using a method originally proposed by Oliver and Pharr, which fits a power-law function to the unloading curve. The qualitative method of microstructure analysis of the samples has been examined before and after laser irradiation at different test conditions to explain the change in mechanical properties according to the change in microstructure features.
\end{abstract}

\section{KEY WORDS}

Surface treatment, Iron alloys, Microstructure, Laser applications, Ultraviolet sources.

\footnotetext{
* Dr. Eng., Consultant in materials sciences \& materials applications, Egypt. Email: Hebatalrahman11@yahoo.com, Hebatalrahman@Naseej.com.
} 


\section{INTRODUCTION}

\section{Methods of Treating and Finishing in Building}

Coating of surfaces: For civil engineering projects the most common method of providing protection is the application of a protective coating during construction. Over the years the specifications for such coatings have been developed such that modern specifications can be used with a high degree of confidence, with respect to the anticipated performance of the coating specification [1]. However, even with modern coating specifications it is impossible to achieve the required design life using a protective coating without very significant maintenance several times within the design life. For example, Highways Agency standard specifications assume the maximum period to first maintenance of 25 years and even the most optimistic assessment of other, more modern specifications would not extend this much beyond 30 or 35 years $[2,3]$.

Galvanization: Steel can be coated with a variety of metals. The term galvanized steel means that it is coated with zinc. Galvanized steel is made by dipping the steel in a hot bath of molten metal $[4,5]$.

Alloying Elements Additions: Alternative approaches to durability have been explored and used in bridge construction, most notably through the use of weathering steels. These are carbon steels with minor alloying additions of copper that form a stable layer on the surface of the steel and thereafter corrode much more slowly than conventional structural steels, these materials do work and need maintenance [6-8]. Within the design life; provided the material is treated correctly and used in an appropriate environment (essentially one that is free of excess pollutants, chlorides and is regularly wetted by rain and dried. These environmental constraints do somewhat limit the use of the material as does the appearance of the steel which to the layman appears to be simply rusty steel. As with the case of carbon steel, structural steel (even in the coated form) represents a material that is not inherently durable in most service environments $[9,10]$.

Development of new alloys: The obvious solution to this would be to use duplex stainless steels, which have increased yield strength. However, in many instances the design of longer span structures will be controlled, at least in part, by considerations of deflections as much as strength. Given the elastic modulus of duplex steel is very similar to that of carbon steel there may be little benefit in using this material $[11,12]$.

There are applications where stainless steel is used as a replacement for carbon steel and there is scope to increase the use of stainless steel in the future. The areas of use of stainless steel can be broadly considered as structures needs good appearance and corrosion resistances [13-16], in these examples the stainless steel was not used simply for appearance it was used as primary structure $[17,18]$.

Buckling: It is well-known that the interaction of buckling modes leads to pronounced imperfection sensitivity and unstable post-buckling response. For stainless steel structural members, this interaction is influenced by gradual yielding 
which leads to a loss of stiffness and buckling capacity under increasing stress [19, 20].

\section{EXPERIMENTAL WORK}

\section{Material}

The alloy used through this work was supplied by Sandvik Co, France in the form of sheets of stainless steel AISI 304 commercial grade. The samples were irradiated by laser. Table (1) shows the laser irradiation conditions of the samples.

Table (1). Laser Irradiation Conditions.

\begin{tabular}{|c|c|c|c|c|}
\hline Type & $\begin{array}{l}\text { Whylength } \\
\text { IIn }\end{array}$ & Ho of pulves & $\begin{array}{l}\text { Energy per } \\
\text { pulse nJ }\end{array}$ & $\begin{array}{l}\text { Repetilion rate } \\
\text { (H) }\end{array}$ \\
\hline Eximi & TW 193 & 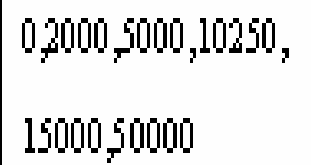 & 6 & 2000 \\
\hline
\end{tabular}

\section{Nano Indentation Measurements}

The Nano test is a pendulum-based depth-sensing system, the sample mounted vertically and the load applied electromagnetically. Current in the coil causes the pendulum to rotate on its frictionless pivot so that the diamond probe penetrates the film surface. Test probe displacement is measured with a parallel plate capacitor with sub-nm resolution. A Berkovich (three-sided pyramidal) diamond indenter was used for all the indentation testing. In view of the rounding of the indenter at the tip, it is necessary to determine the area function of the indenter to obtain meaningful values of hardness and modulus. The area function for the diamond, which is used to determine the contact area for a given depth, was calibrated by indentations to different depths into fused quartz (load range: $0.5-200 \mathrm{mN}$ ). Fused quartz is an isotropic material used as a calibration standard by the nanoindentation community because its hardness and elastic modulus do not vary significantly with indentation depth. The area function for the diamond used in this work was:

$$
A=23.1 h^{2}{ }_{c}+1278 h_{c},
$$

where $h_{c}$ is the contact depth. For comparison, the area function of an ideal Berkovich diamond is $A=24.5 h^{2}$. Fused quartz was also used to determine the instrument (frame) compliance, which was $0.81 \mathrm{~nm} / \mathrm{mN}$ for the instrument used in this work. The measured depth is adjusted for the effect of instrument compliance in the instrument software. 
Nano-indentation was used to determine film hardness and elastic modulus using a nano-test 600 instrument from Micro Materials Ltd with a Berkovich (three-sided pyramidal) diamond indenter. The peak loads in the rage $1-200 \mathrm{mN}$ were used, with loading rate $=$ unloading rate that were varied in proportion to the peak loads starting at a value of $0.05 \mathrm{mN} / \mathrm{s}$ for the 1 indentations, while common experimental conditions as initial (contact) load $0.05 \mathrm{mN}$ and holding period at peak load $10 \mathrm{~s}$ were used for all the measurements. The indentations were repeated at least five times at each load on different regions of the sample surface apart $100 \mathrm{~m}$. The hardness and reduced modulus have been determined from these indentation curves using a method originally proposed by Oliver and Pharr, which fits a power-law function to the unloading curve $[17,21]$.

\section{Qualitative Analysis}

The specimens were prepared for examination first by grinding on different grades of silicon carbide "SiC" papers coarse grinding followed by fine grinding at $180,240,320,400,600$, and 800 finally polishing was conducted with Alumina powder $(3 \mu \mathrm{m})$ size. The details of the microstructure were revealed after etching by standard etching solution of the alloy selected. All specimens were etched and polished several times to obtain best results and to produce a uniform level of sample examination. Table (2) shows the etching solutions used for the investigated alloys $[17,22]$.

Table (2). The etching solutions used for all alloys

\begin{tabular}{|c|c|c|c|}
\hline Alloy & Etching & condidions & Remarks \\
\hline Statiless & Hydrodiotic and (4]\%) & $45 \mathrm{ml}$ & Itumerged \\
\hline Stegid4 & $\begin{array}{l}\text { Nittic acid (1.40) } \\
\text { thethatiol }\end{array}$ & $\begin{array}{l}15 \mathrm{mLl} \\
20 \mathrm{~m} \mathrm{n}\end{array}$ & $5-15 \sec$ \\
\hline
\end{tabular}

The surfaces of the samples before and after laser irradiation were examined using an Olympus optical microscope Model BHM at selected magnification.

\section{RESULTS AND DISCUSSIONS}

\section{Laser Irradiation and Nano-Measurements}

Nano indentation test was repeated at the same conditions and the same test procedures at a wavelength of $193 \mathrm{~nm}$. The samples were irradiated at $193 \mathrm{~nm}$ at the same power of $6 \mathrm{~mJ}$ and repetition rate of $200 \mathrm{~Hz}$.

Figure (1) and Figure (2) show the variation of stiffness with depth and load as a function of the number of pulses respectively. In general, the stiffness increased gradually with indentation depth and load. The minimum values of stiffness were recorded close to the surface of the sample with a slight increase for the samples irradiated at 2000 pulses. On the other hand a significant increase in stiffness was recorded for samples irradiated at higher number of pulses. The recorded variation 
in stiffness with indenter depth and load show that, indentation with number of pulses of 5000 pulses produces the highest stiffness, while increasing number of pulses up to 15000 pulses reduces indentation stiffness. Figure (3) shows the variation of hardness with maximum depth for the austenitic stainless steel 304 irradiated by Excimer laser $193 \mathrm{~nm}$ at $200 \mathrm{~Hz}, 2.2 \mathrm{~mJ}$ at different number of pulses. The higher number of pulses the higher the hardness at an indentation depth of about $750 \mathrm{~nm}$ at number of pulses from 0 to 5000 pulses. Figure (4) shows the variation of hardness with maximum load for the austenitic stainless steel 304 irradiated by Excimer laser $193 \mathrm{~nm}$ at $200 \mathrm{~Hz}, 2.2 \mathrm{~mJ}$, at different number of pulses. The hardness decreased as the load increased, maximum hardness is at the surface, the higher number of pulses the higher the hardness at maximum load of $100 \mathrm{mN}$. Figure (5) shows the variation of reduced modulus with maximum depth for the austenitic stainless steel 304 irradiated by Excimer laser $193 \mathrm{~nm}, 200 \mathrm{~Hz}, 2.2 \mathrm{~mJ}$, at different number of pulses. The variation of reduced modulus is significant at an indentation depth of $500 \mathrm{~nm}$. Figure (6) shows the variation of reduced modulus with load for the austenitic stainless steel 304 irradiated by Excimer laser $193 \mathrm{~nm}, 200 \mathrm{~Hz}$, $2.2 \mathrm{~mJ}$, at different number of pulses. The change in reduced modulus is less pronounced than variation in hardness at the same range of number of pulses. The gradual decrease in modulus is at maximum load $120 \mathrm{mN}$.

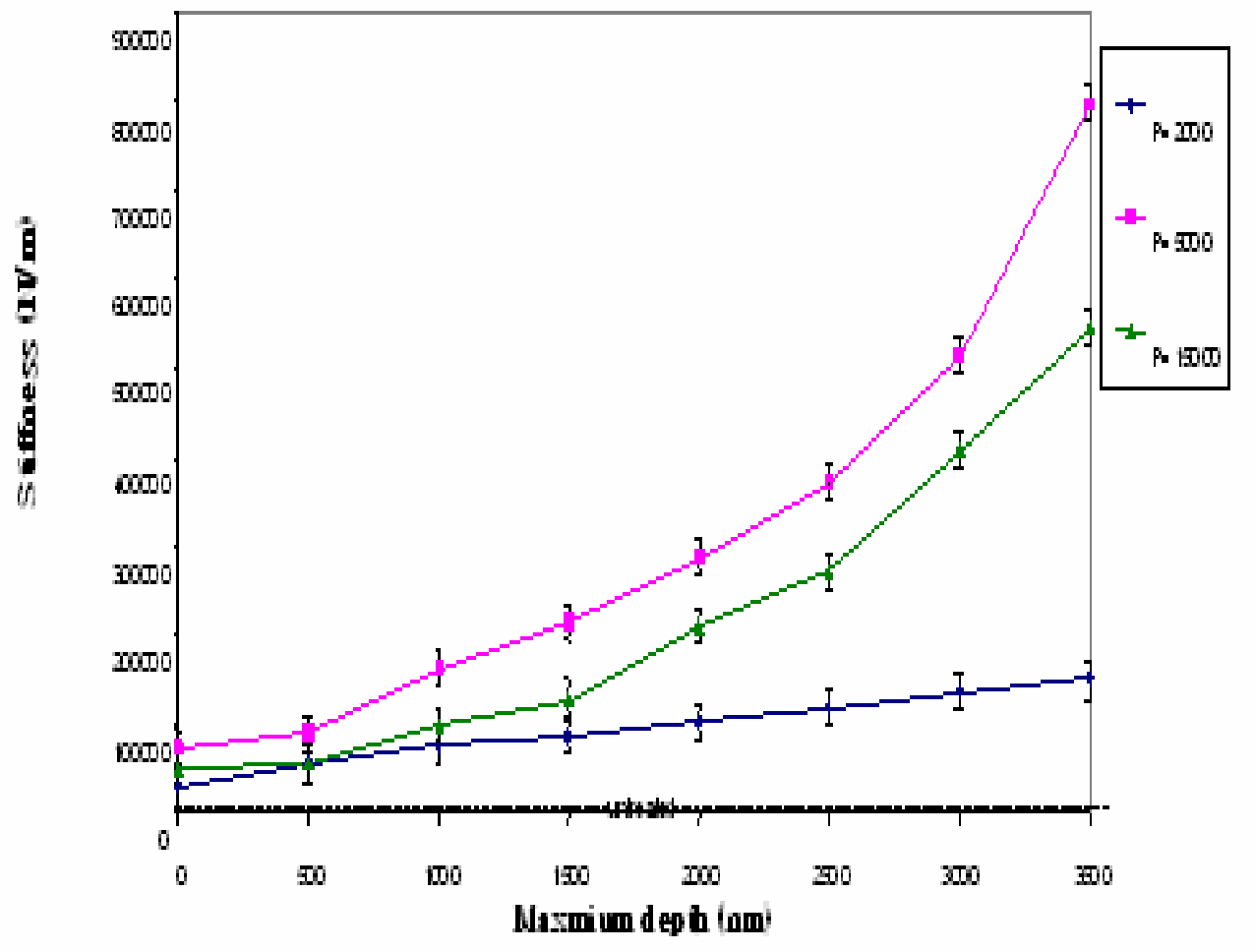

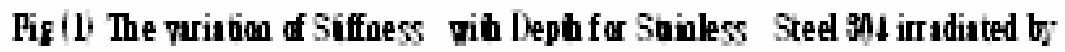
Hixcimer La ser 10 fom $0 \mathrm{~mJ} 200 \mathrm{~Hz}$ it liffer ent llumber of Fulses 


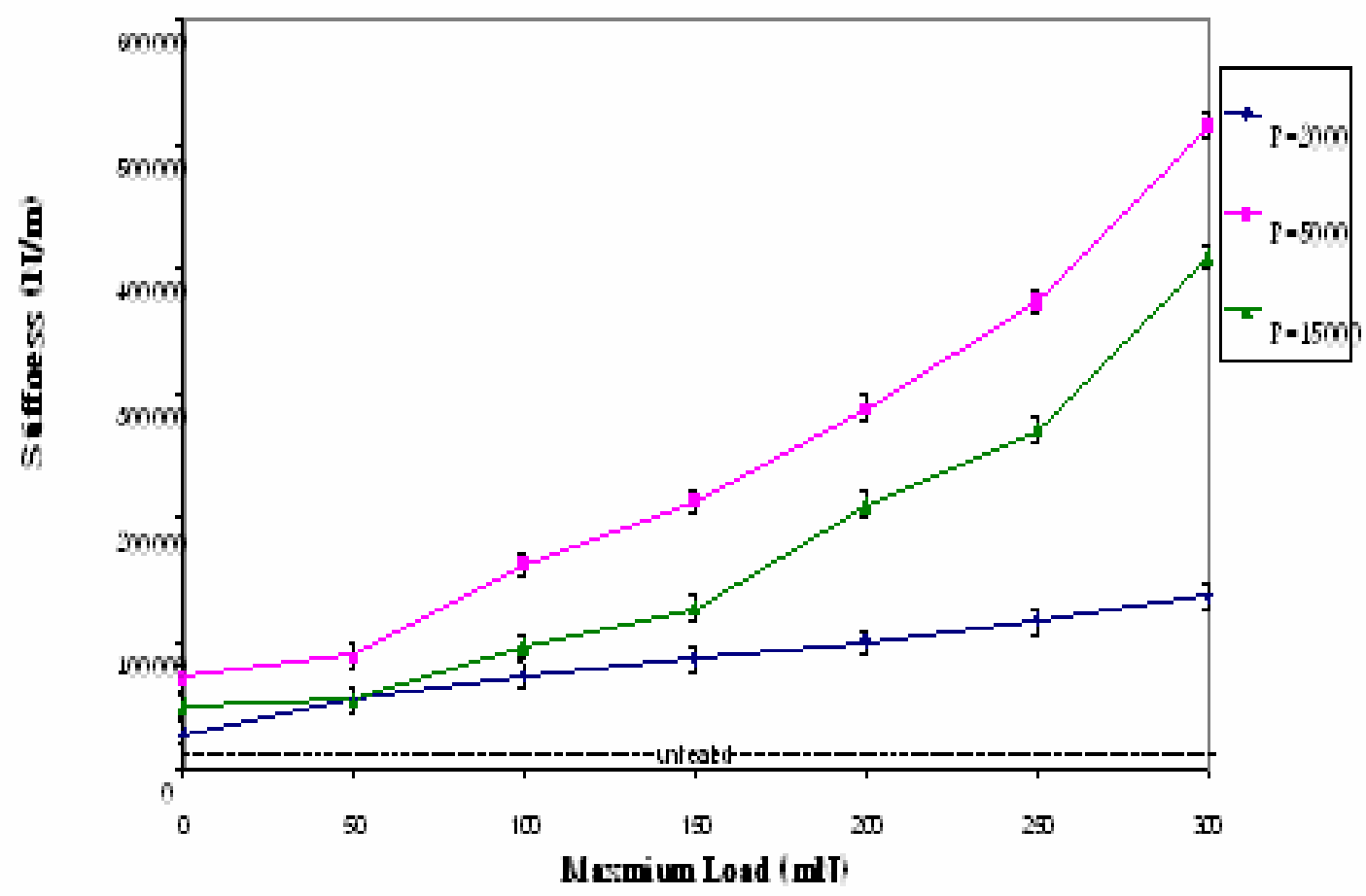

Pis (2) The variation of Siffness vith Load for Suinless Steel solirradiated by excimer La ser $193 \mathrm{~mm}$ 6m. $200 \mathrm{~Hz}$ a t Deffer ent llumber of $P$ uses

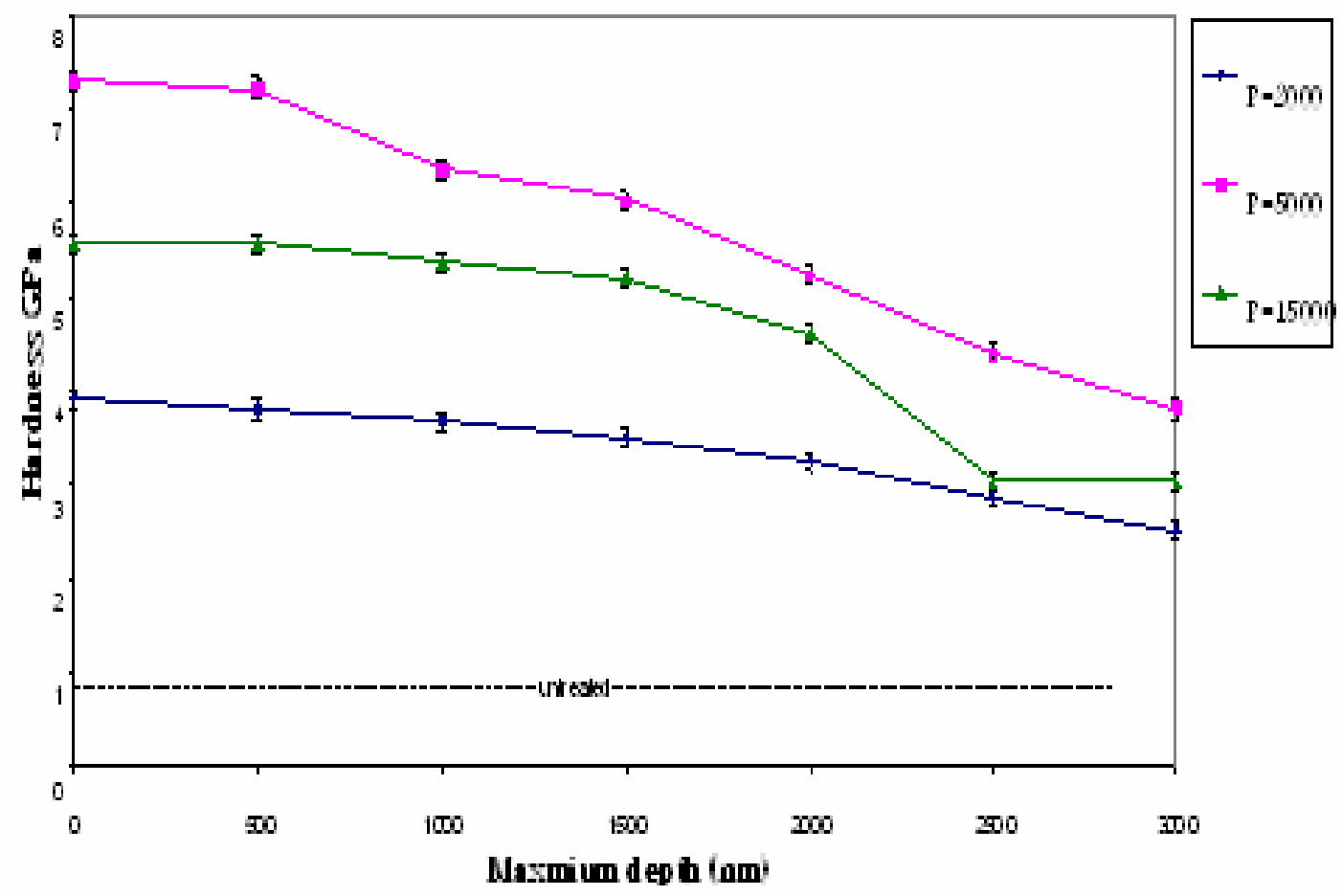

Pig (s) The puriation of Hardness with Deph for Stainless Steel $30 \downarrow$ irradiated by excimer La ser $1290 m 6 \mathrm{~mJ}, 200 \mathrm{~Hz}$ at Diff er ent lIumber of $\mathrm{F}$ uses 


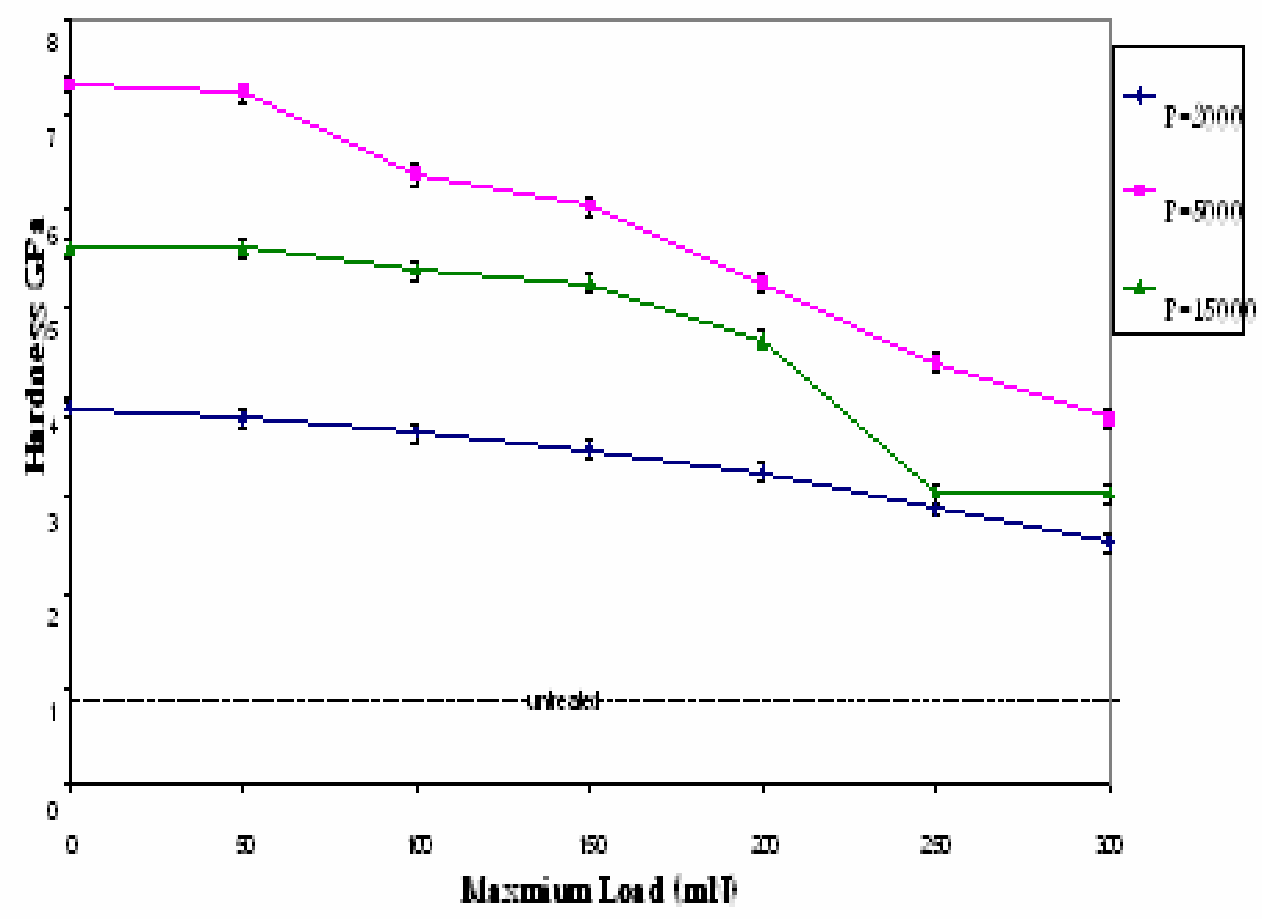

Pigi $\downarrow$ The varintion of Hardaess with Load for Suinless Steel gotirradinted by excimer La ser $1990 \mathrm{~nm} 6 \mathrm{~mJ}$. $200 \mathrm{~Hz}$ a at Diff er ent lIumber of $\mathrm{Fu}$ ses

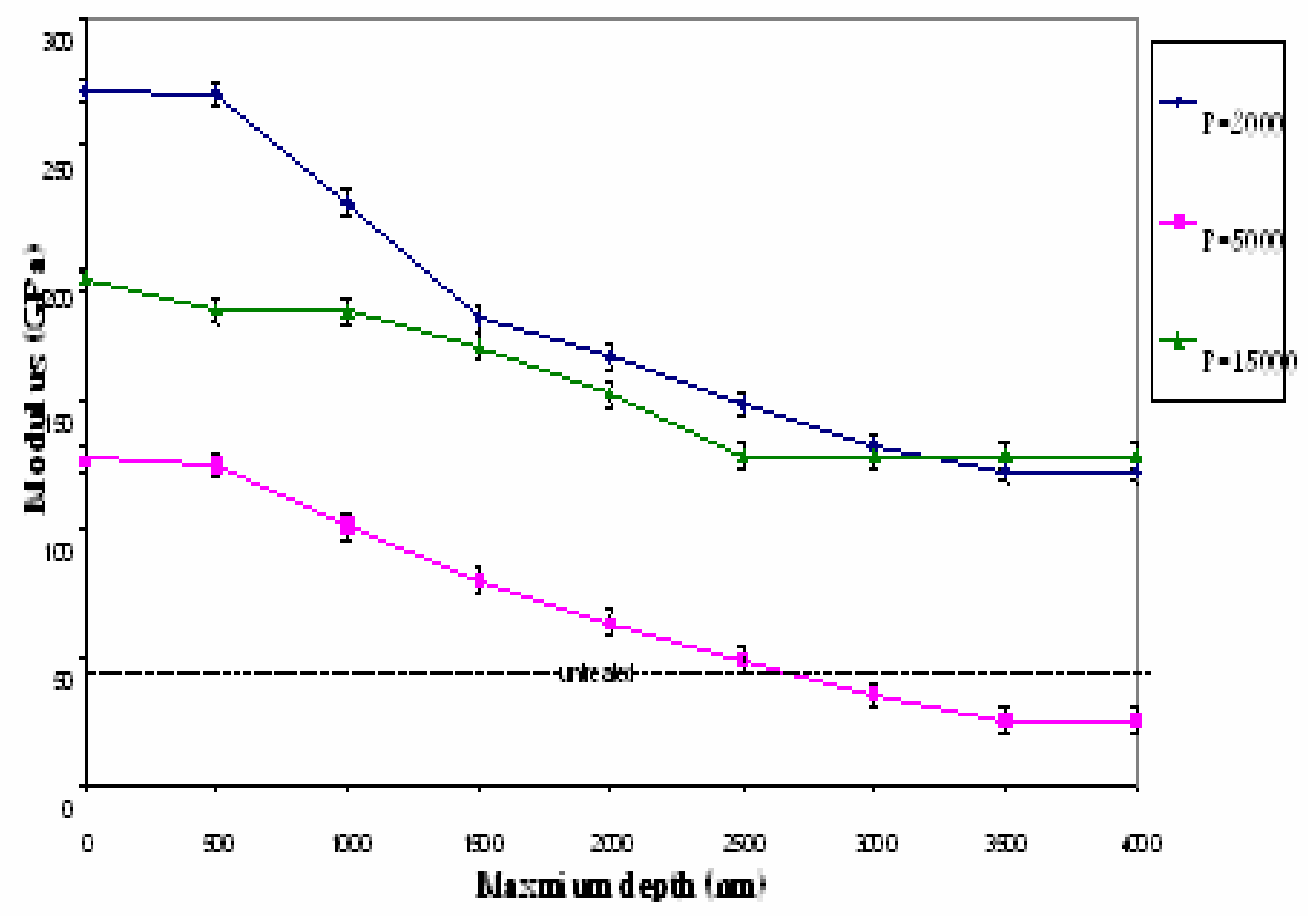

Pig (5) The puriation of Modulus vih Dep $\mathrm{t}$ for Stainless Steel $\$ 0 \downarrow$ irndated by excimer Laser $1930 \mathrm{~m}$ 6mJ. $200 \mathrm{~Hz}$ at Differ ent llumber of $F$ ulses 


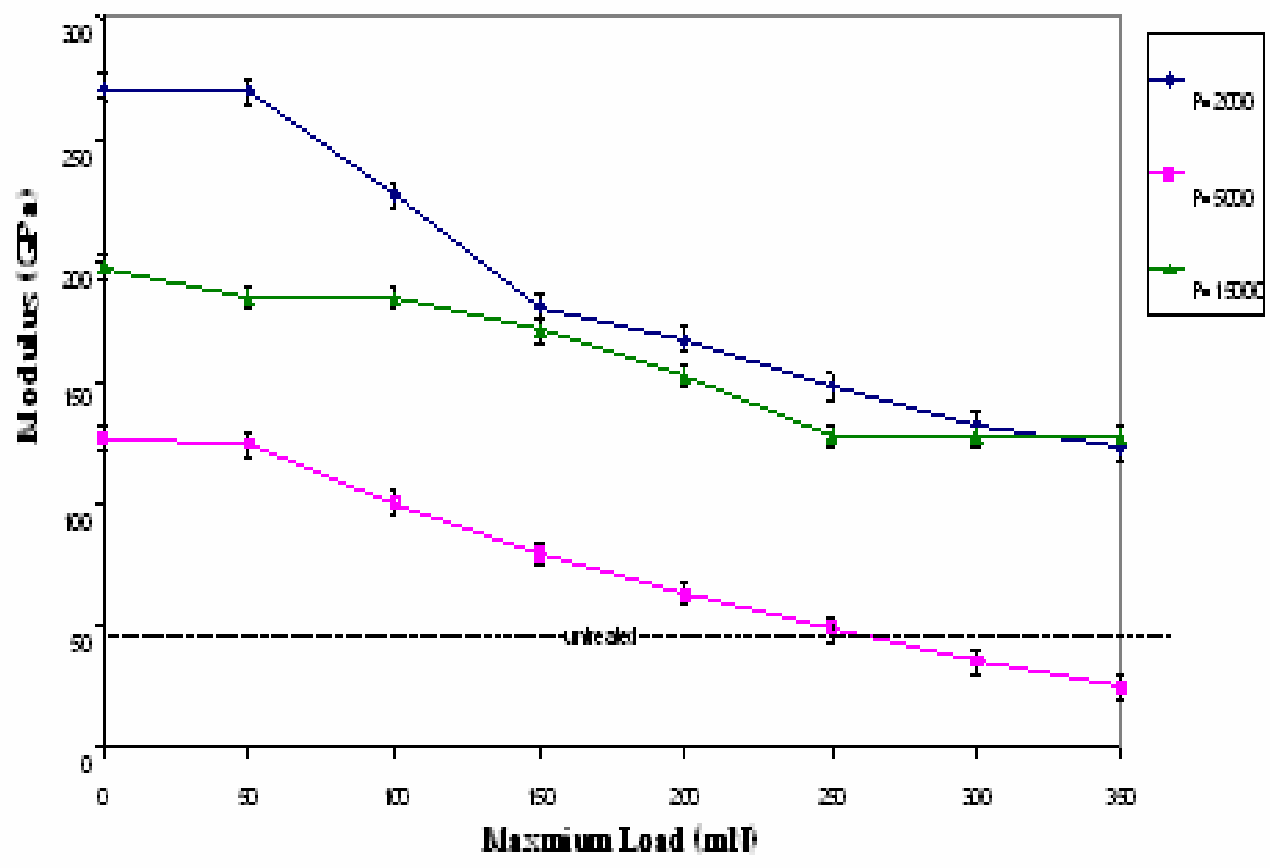

Pig (6) The Variation of Modulus with Load for Suinless Steel sol irradiated by excimer Laser $1990 \mathrm{~m} 6 \mathrm{~mJ} .20 \mathrm{CHz}$ at Irffer ent lIumber of Fuses

\section{Qualitative Analysis Results}

When a laser beam impinges on a surface, part of its energy is absorbed at the surface. If the power density of the laser beam (usually given in watts per square centimeter) is sufficiently high, heat will be generated at the surface faster than heat conduction to the interior, and the temperature on the surface layer will increase rapidly. At very short time, a thin surface layer will have reached phase transition temperatures; where as the interior of the work-piece is still cold. Lasers can generate very intense energy fluxes at the work piece surface. Because ferrous materials are very good heat conductors, the high heat fluxes generated by lasers are most suitable to heat the surface layer to phase transition levels without affecting the bulk temperature of the sample. The ensuing self-quenching is rapid enough to eliminate the need for external quenching to produce the hard martensite in the heated surface.

\section{Microstructure Examination}

Figure (7) shows the variation in microstructure of stainless steel 304 irradiated by Excimer laser $193 \mathrm{~nm}$. Laser irradiation leads to change in grain size. At lower number of pulses, grain size increases and grains refinement were occurred. When the number of pulses increased over 10250 pulses and grain growth happened; this is the main reason for the decrease in mechanical properties at higher number of pulses.

In this type of stainless steels, $\mathrm{Y}$-phase persists at room temperature leading to the familiar group of austenitic steels based on \% $\mathbf{C r}$ (percentage of Chromium) and, 


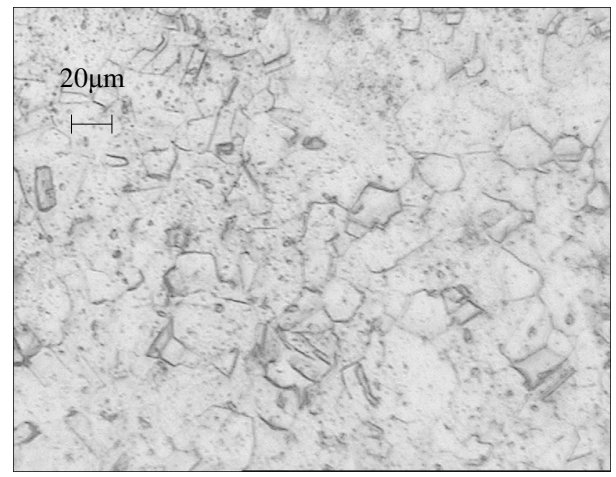

untreated

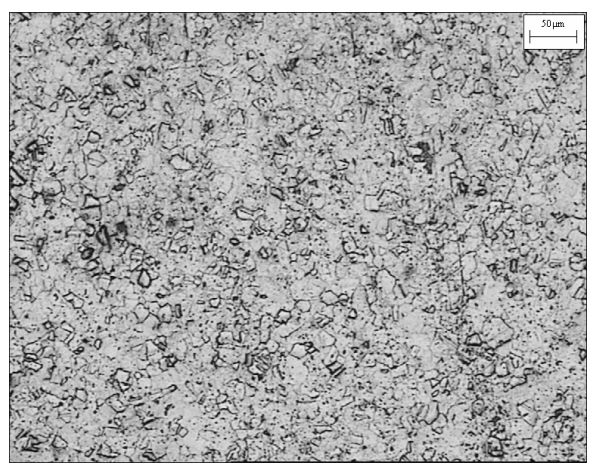

(c)5000pulses

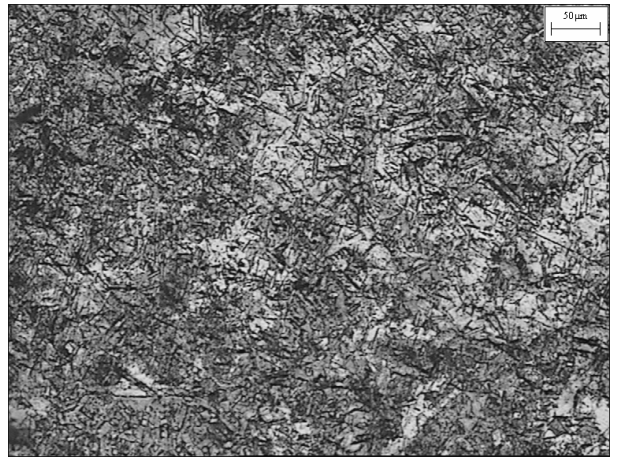

(b)2000pulses

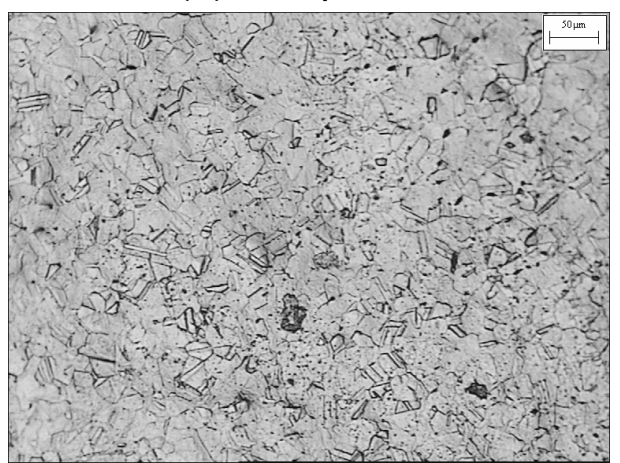

(d)15000pulses

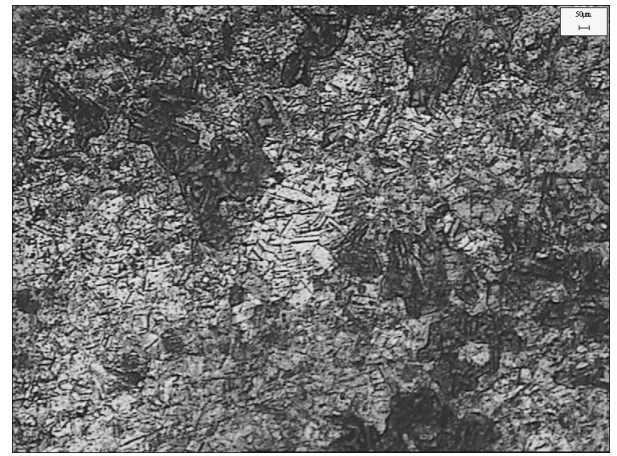

(e)50000pulses

Fig (7). The Effect of Excimer Laser irradiation at $193 \mathrm{~nm}, 6 \mathrm{~mJ}, 200 \mathrm{~Hz}, 100 \mathrm{x}$ at. Different Number of Pulses on the microstructure of Stainless Steel 304

$\% \mathbf{N i}$ (percentage of Nickel). This particular composition formed because minimum nickel content is required to retain $\mathrm{y}$ at room temperature. The $18 \mathrm{Cr} \mathbf{8 N i}$ steel, in fact, has an Ms martensite transformation just below room temperature on cooling, it will transform very substantially to martensite. This significant improvement in hardness after laser irradiation is due to the alloying elements found in this type of steel.

This result agrees with the published results. For example in 2000 scientists [18] published a group of papers about the improvement in micro-hardness and corrosion due to laser irradiation of some types of steels and prove that the effect is not only limited on the surface but may be reach to about $0.7 \mathrm{~mm}[11,18]$ as well. In the current study, the laser effect was reached to about $500 \mu \mathrm{m}$. The mechanism of 
laser metal interaction at different irradiation conditions may explain the deviation between the current study and published results.

The laser interaction with the alloys is a very complex phenomenon. A mechanism of laser irradiation at high power rating was explained according to the following procedures: a point on the surface within the path of the beam is rapidly heated as the beam passes. This area is subsequently cooled rapidly by heat conduction to the interior after the beam has passed [20]. The material will harden to the desired depth. The major advantages of laser surface hardening include close control of the power input with modern metalworking lasers; the high power density provided by the laser, which in turn maximizes the total energy input and the ability of the laser to reach normally inaccessible areas on the work-piece surface. Because no vacuum or protective atmosphere enclosure is needed and because the distance from the work piece to the last optical element of the laser system can be quite long. It is possible to process very large or irregular-shaped work pieces [10,12]. The only disadvantages in this technique that some parts at the sample surface were burned due to high power rating of $193 \mathrm{~nm}$ which leads to oxidation of some parts on the surface of the alloy at 50000 pulses.

\section{CONCLUSIONS}

1. Laser surface irradiation process is a very complicated process, it is found to be affected by the microstructure.

2. The mechanical properties such as hardness, modulus and stiffness of the austenitic stainless steel were improved. Hardness and modulus were decreased with both depth and load but stiffness was increased.

3. The variation in microstructure of stainless steel 304 irradiated by Excimer laser $193 \mathrm{~nm}$. Laser irradiation leads to change in grain size.

4. At lower number of pulses, grain size increases and grains refinement were occurred.

5. The maximum improvement in nano-hardness and reduced modulus has been investigated in the surface of the sample and rapid decrease in the mechanical properties has been recorded along the depth.

6. When the number of pulses increased over 10250 pulses, grain growth happened and which is the main reason for the decrease in mechanical properties at higher number of pulses.

\section{REFERENCES}

[1] M. Jergel, S. Luby, A. Anopchenko, E. Majkova, M. Spasova, V. Holy, M. Brunel, A. Luches, M. Martino: An Interplay Between the Structure and Giant Magnetoresistance in Laser Treated Ag/Co Multilayers, Superficies y Vacio 8 (1999) 28-32.

[2] S. Acquaviva, M. Fernandez, G. Leggieri, A. Luches, M. Martino, A. Perrone, Pulsed Laser Ablation Deposition of Thin Films on Large Substrates, Appl. Phys. A 69 (Suppl.) (1999) S471-S474. 
[3] M. Jergel, A. Anopchenko, E. Majkova, M. Spasova, S. Luby, V. Holy, M. Brunel, A. Luches, M. Martino: Excimer Laser Treated Ag/Co Multilayers exhibiting Giant Magnetoresitance Effect, Superficies y Vacio 9 (1999) 193198.

[4] S. Luby, E. Majkova, M. Spasova, M. Jergel, R. Senderak, E. D’Anna, A. Luches, M. Martino: Structure and In Depth Concentrations in Excimer Laser Irradiated Ag-Co and Pb-Co co deposited films, Functional Materials 6 (1999) 565-567.

[5] A. Luches, A. Perrone, S. Acquaviva: A system for laser ablation deposition of thin films on large substrates, Vuoto, Vol. XXVIII, N. 3-4 (1999), 24-26

[6] S. Luby, E. Majkova, M. Jergel, R. Senderak, E. D’Anna, G. Leggieri, A. Luches, M. Martino: Structure and in-Depth Concentrations in Excimer Laser Irradiated Pb-Co Codeposited Films, Thin Solid Films 359, (2000) 141-145.

[7] N. Laidani, M. Anderle, R. Canteri, L. Elia, G. Leggieri, A. Luches, M. Martino,V. Micheli, G. Speranza: Structural and Compositional Study of B-CN Films Produced by Laser Ablation of $\mathrm{B}_{4} \mathrm{C}$ Targets in $\mathrm{N}_{2}$ Atmosphere, Appl. Surf. Sci. 157 (2000) 135-144.

[8] V. S. Teodorescu, A. Luches, R. Dinu, A. Zocco, M. F. Ciobanu, M. Martino, V. Sandu, M. Dinescu: Influence of the Substrate Temperature on BCN Films Deposited By Sequential Pulsed Laser Deposition, Appl. Phys. A 69 (Suppl.) (1999) S667-S670.

[9] S. Acquaviva, G. Leggieri, A. Luches, A. Perrone, A. Zocco, N. Laidani, G. Speranza, M. Anderle: Cubic boron nitride deposition on silicon substrates at room temperature by $\mathrm{KrF}$ excimer laser ablation of $\mathrm{h}-\mathrm{BN}$ targets, Appl. Phys. A 70 (2000), 197-201.

[10] S. Acquaviva, A. Perrone, A. Zocco, A. Klini, C. Fotakis: Deposition of carbon nitride films by reactive sub-picoseconds pulsed laser ablation, Thin Solid Films, 373/1-2 (2000), 266-272.

[11] S. Acquaviva, E. D’Anna, M. Fernández, G. Leggieri, A. Luches, M. Martino, A. Perrone: Pulsed laser ablation deposition of thin films on large and threedimensional substrates, Vuoto XXIX, N. 1-2 (2000), 63-64.

[12] S. Acquaviva, M.L. De Giorgi, M. Fernández, G. Leggieri, A. Luches, M. Martino, A. Zocco: Pulsed laser deposition of thin $\mathrm{SiO}_{2}$ and ITO films for optoelectronic applications, Vuoto XXIX, N. 3-4 (2000), 44-46.

[13] G. Barucca, G. Majni, P. Mengucci, G. Leggieri, M. Martino,: Monoclinic Carbon Nitride Phase Coherently Grown on Si(001) Substrates, Jou. Appl. Phys. 89(6) (2001) 3494-3497.

[14] S. Luby, E. Majkova, M. Jergel, G. Leo, S. Tundo, L. Vasanelli, E. D’Anna, A. Luches, M. Martino: The Thermal Stability of Tungsten/Silicon Multilayered Nanostructures, Materials Science and Engineering C 15 (2001) 187-189.

[15] C. Dutouquet, S. Acquaviva, J. Hermann, Detection of boron nitride radicals by emission spectroscopy in a laser-induced plasma, Spectrochimical Acta B: Atomic Spectroscopy 56B 6, (2001), 629-635.

[16] J. Hermann, F. Coursimault, O. Motret, S. Acquaviva, A. Perrone: Investigation of silicon oxide emission spectra observed in a pulsed discharge and a laser-induced plasma, J. Phys. B: At. Mol. Opt. Phys. 34 (2001), 19171927.

[17] M. De Sario, G. Leggieri, A. Luches, M. Martino, F. Prudenzano, A. Rizzo: Pulsed Laser Deposition Of Praseodymium-Doped Chalcogenide Thin Films, Appl. Surf. Scie. 186 (2002) 216-220. 
[18] P. Mengucci, G. Barucca, G. Majni, A. Di Cristoforo, G. Leggieri, M. Martino: Coherent carbon nitride phases grown on $\mathrm{Si}$ substrates by reactive laser ablation, Recent Res. Devel. Applied Phys. 5 (2002) 69-87.

[19] A. D'Orazio, M. De Sario, L. Mescia, V. Petruzzelli, F. Prudenzano, A. P. Caricato, G. Leggieri, M. Martino: Design and Fabrication of Praseodymium Doped Optical Waveguides, Proc. SPIE 4645 (2002) 174-182.

[20] A. P. Caricato, M. Fernandez, G. Leggieri, A. Luches, M. Martino F. Prudenzano: Pulsed laser Deposition of Films and Multilayers for Optoelectronic Applications Proc SPIE 4762 (2002) 41-51.

[21] S. Acquaviva and M.L. De Giorgi: Study of kinetics of atomic carbon during laser ablation of graphite in nitrogen atmosphere by time- and spaceresolved emission spectroscopy, Appl. Surf. Sci. 186 (2002) 329-334.

[22] S. Acquaviva and M.L. De Giorgi: High-resolution investigations of $\mathrm{C}_{2}$ and $\mathrm{CN}$ optical emissions in laser-induced plasmas during graphite ablation, J. Phys. B: At. Mol. Opt. Phys. 35 (2002) 795-806. 